\title{
Present position of the electrical stimulation test
}

\author{
H. BURGE, T. B. L. ROBERTS, R. D. STEDEFORD, AND M. J. LANCASTER
}

From West London Hospital

The electrical stimulation test to ensure complete gastric vagotomy at the time of operation was first described by Burge and Vane in 1958.

THE PRINCIPLE OF THE TEST

No drugs with an anticholinergic action should be used for treatment during the few weeks preceding operation. Simple antacids only may be given. Antacids, containing belladonna and drugs of the phenothiazine group, in particular, must be avoided. Premedication for the operation should be limited to papavaretum and anaesthesia maintained with thiopentone, gallamine, nitrous oxide, and oxygen only.

An electrode is placed around the lower oesophagus. A cuffed oral gastric tube seals the lower oesophagus and brings intact vagal nerve trunks into good contact with the silver electrodes. An intestinal clamp is placed across the prepyloric stomach. The stomach is then distended with air to a pressure of about $70 \mathrm{~mm} \mathrm{H}_{2} \mathrm{O}$, and the pressure recorded on a suitable instrument. Even the smallest intact nerve trunk causes a pressure rise on stimulation. When nerve section is complete there is no rise whatsoever of the gastric pressure; often there is a slight fall. The principle is illustrated in Figure 1.

THE ELECTRICAL STIMULATION TEST MARK III

The mark III instrument (Fig. 2) is built into a standard sphygmomanometer box. Coloured water replaces the mercury in the manometer. A thin washer with a tiny hole is placed at the base of the manometer to damp the changes of pressure caused by respiration.

The transistorized stimulator is built into the base of the box where, too, the batteries are housed.

The electrode (Fig. 3) is stimulated by a square wave current of 40 volts and a frequency of 15 per second. Figure 4 shows the cuffed gastric tube through which the gastric pressure is measured.

A rise of pressure on stimulation of as little as $2 \mathrm{~mm}$ $\mathrm{H}_{2} \mathrm{O}$ is regarded as significant and indicative of incomplete nerve section. Working to these standards, a surgeon well experienced in vagotomy may expect to achieve complete nerve section without the test in only $50 \%$ of cases.

The set is now supplied with a simple electrode (Fig. 5) for any peripheral nerve stimulation. It is of particular use in parotidectomy.

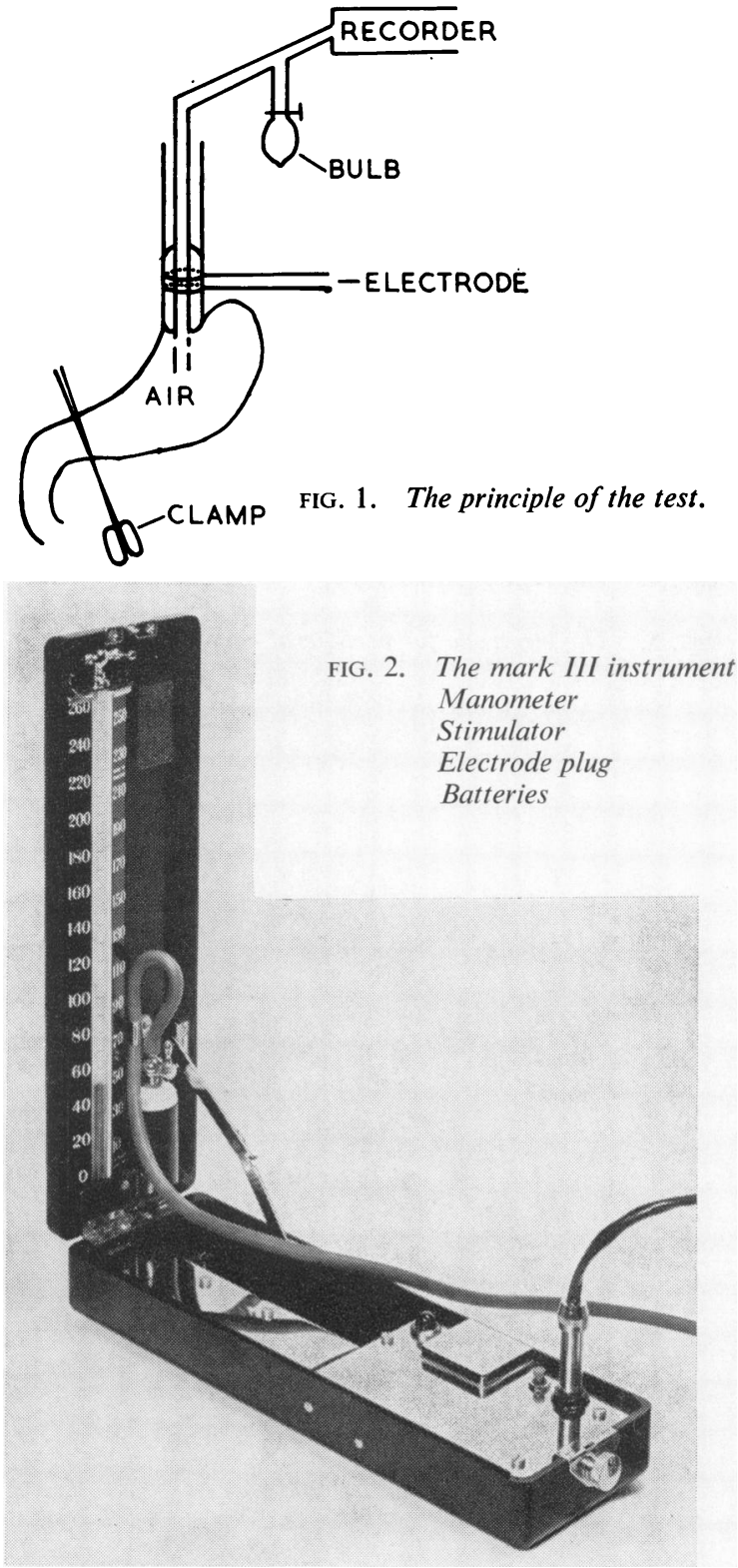




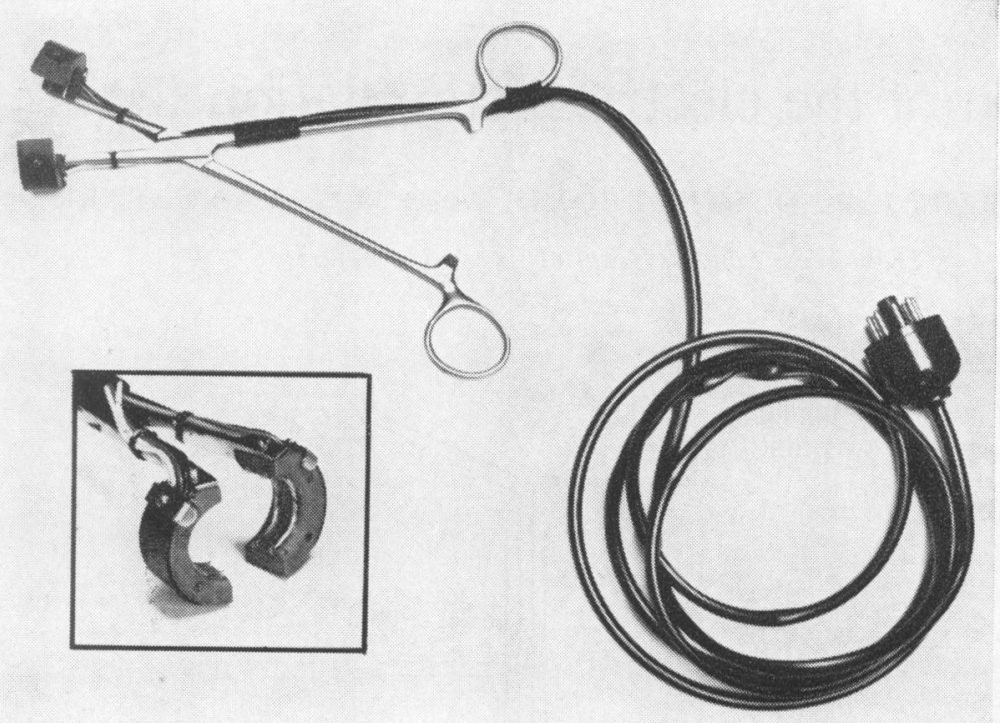

FIG. 3.

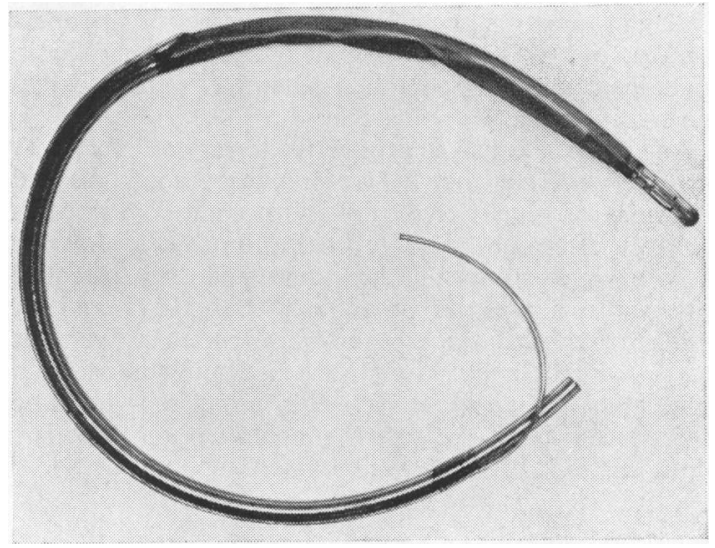

FIG. 3. The electrode.

FIG. 4. The cuffed gastric tube.

FIG. 5. The electrode for peripheral nerve stimulation.

FIG. 4.



FIG. 5. 


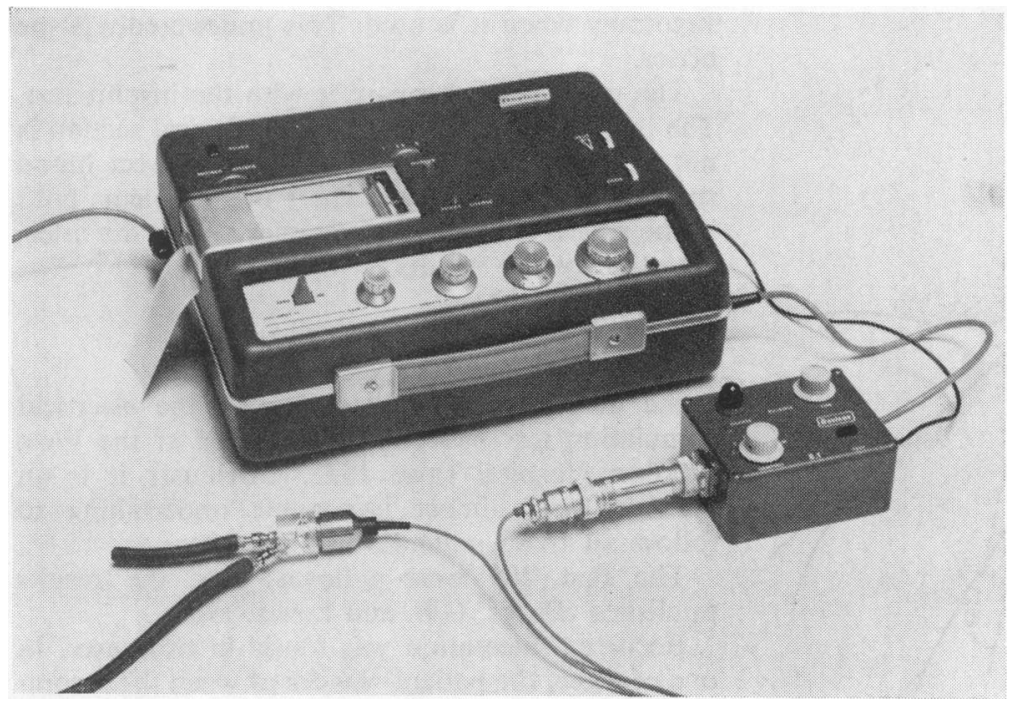

FIG. 6. The pressure transducer and pen recorder.

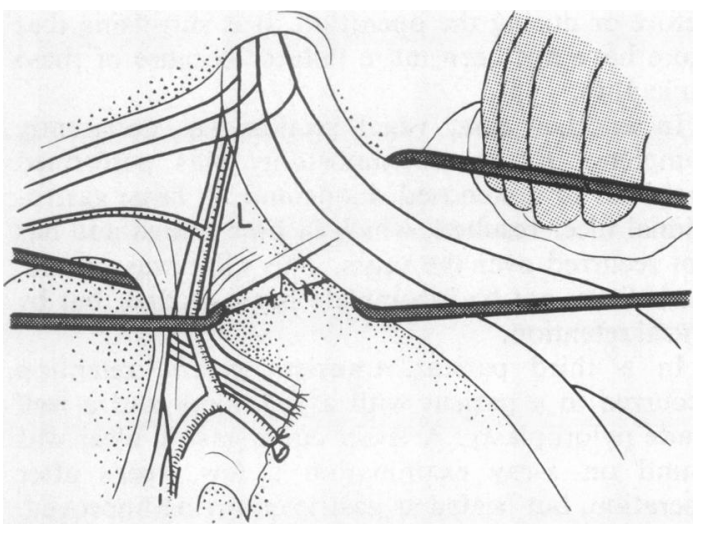

FIG. 7. The preliminary test.

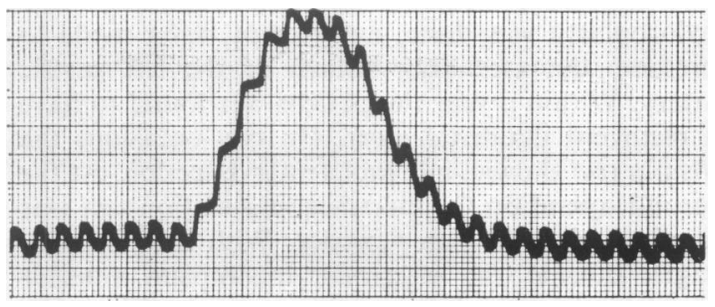

FIG. 8. The rise of pressure at the preliminary test.
THE ELECTRICAL STIMULATION TEST WITH PEN RECORDING

The mark III instrument with its water manometer is satisfactory and comparatively : cheap. There are, however, obvious advantages in a written record. The pressure transducer and pen recorder (Fig. 6) are expensive, but many hospitals have suitable means of pressure recording for other purposes.

As with the mark III instrument, the preliminary test, used to prove that no anticholinergic drugs have been given to paralyse the vagus and so invalidate the test, is applied after posterior selective- vagotomy is complete and the main anterior gastric branch (the nerve of Latarjet) divided (Fig. 7). One or two small anterior trunks seem always to remain intact at this time and respond to stimulation by a rise in pressure (Fig .8).

When anterior selective vagotomy is completed and when, after a careful search for any small intact nerve trunks, vagotomy is thought complete, the final test is made (Fig. 9).

In $50 \%$ of cases, incomplete nerve section will be shown by a small rise in gastric pressure (Fig. 10). A further search must be made and the test repeated, if necessary several times, until nerve section is complete (Fig. 11). Usually when nerve section is complete, there is no change in gastric pressure, but not infrequently there is a fall, as though perhaps in the absence of intact vagal trunks, the sympathetic is in some way stimulated.

\section{THE RESULTS OF THE TEST}

There are two ways of assessing the value of this test. One is by studying over the years the results of 


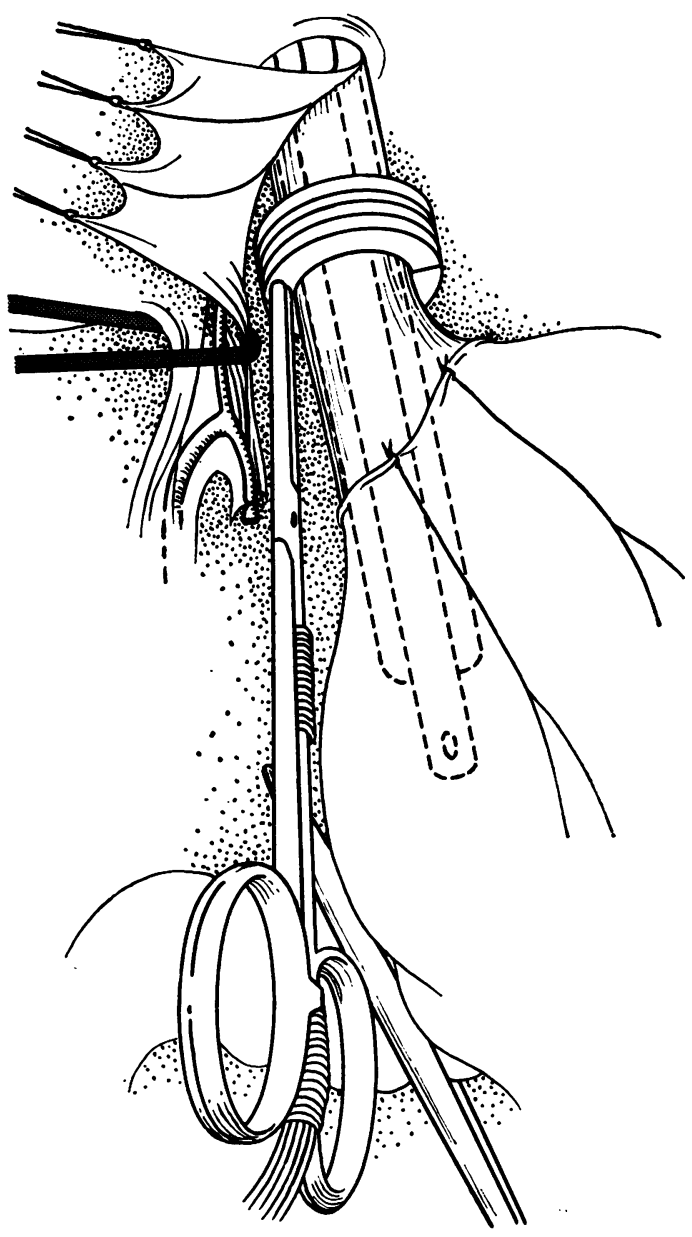

FIG. 9. The final test.

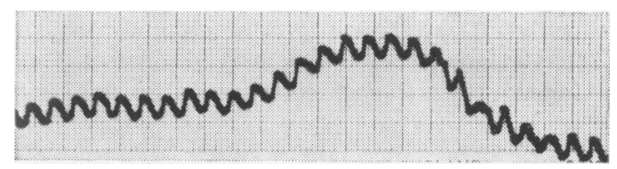

FIG. 10. Incomplete vagotomy.

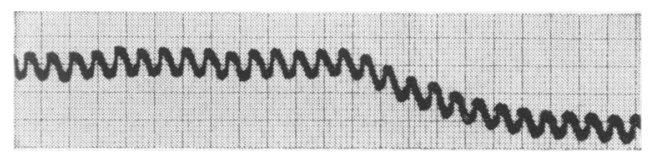

FIG. 11. Complete vagotomy. vagotomy when it is used. This undoubtedly is the better.

The other is to compare it with the insulin test. The insulin test for completeness of vagal section is not free from difficulties even when correct blood sugar levels are attained. There are problems both in the proper collection of samples and in the interpretation of the results.

\section{THE CLINICAL RESULTS}

Some 600 cases of vagotomy with the electrical stimulation test have been performed at the West London Hospital since 1957. Obviously it is an immense and almost impossible undertaking to follow all these patients over the years.

The first 200 were followed and the results published (Burge, Gill, and Lewis, 1964).

Recurrent ulceration was found in two cases. In one of these, the patient was cured when the incomplete nerve section was completed and the gastrojejunostomy taken down and replaced by pyloroplasty. Clearly, there was some fault with the test in this case at the first operation. Over the years, there have been a number of technical problems with the test which have had to be solved, not the least of these being the use of anticholinergic drugs either before or during the operation. It is surprising that there have not been more failures because of these difficulties.

In another case, vagal section was apparently complete, but gastrojejunostomy was performed proximal to a stenosed duodenum. A large gastrojejunal ulcer resulted, which in time healed and has not recurred over the years. This ulcer was caused, we believe, not by incomplete nerve section, but by antral retention.

In a third patient, transient gastric retention occurred in a patient with a vagotomy and a well made pyloroplasty. A lesser curve gastric ulcer was found on $x$-ray examination a few weeks after operation, but healed as gastric emptying improved. It has not recurred.

One other case is known to have undergone gastric resection at another hospital.

In another, bilateral selective vagotomy and pyloroplasty was done, an attempt being made to preserve the ascending branch of the left gastric artery. Within a year the patient was found to have a recurrent duodenal ulcer. On two occasions the insulin test showed incomplete nerve section. At the second operation the electrical stimulation test was applied using the pen recorder. With the posterior vagus outside the electrode, incomplete anterior gastric vagotomy was demonstrated (Fig. 12). The incomplete anterior vagal section was completed 


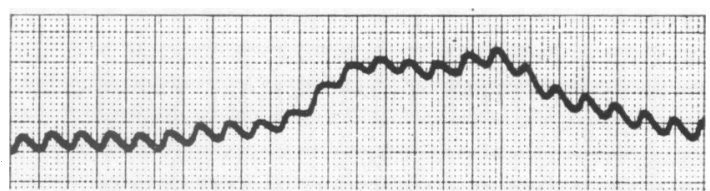

FIG. 12. Incomplete anterior vagotomy.

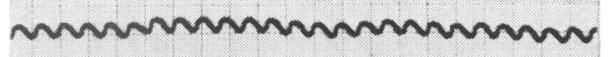

FIG. 13. Complete anterior vagotomy.

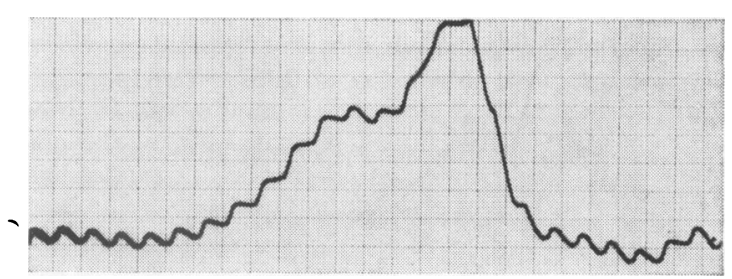

FIG. 14. Incomplete posterior vagotomy.

\section{Mmm}

FIG. 15. Complete gastric vagotomy.

and completeness was proved by the test, again with the posterior nerve outside the electrode (Fig. 13). The posterior vagus was then included in the electrode and incomplete posterior vagal section demonstrated (Fig. 14). This was completed by division of the descending branches of the left gastric artery and complete gastric vagotomy proved by the test with the posterior nerve within the electrode (Fig. 15).

\section{A COMPARISON WITH THE INSULIN TEST}

Twenty-five cases have been tested from 10 days to three months postoperatively, six on two separate occasions. Insulin was given intravenously $(0 \cdot 15$ units/kg body weight) and half-hourly blood sugar estimations and gastric aspirations were continued for the following two hours. A fall of blood sugar to less than $40 \mathrm{mg} / 100 \mathrm{ml}$ was taken as an adequate hypoglycaemic stimulus.

In all these 25 cases the electrical stimulation test was negative at operation. In 10 there was no free acid in the insulin test either before, during, or after the hypoglycaemia. In the remainder free acid was present but the test was still negative according to Hollander's criterion of a rise in free acid concentration of less than $20 \mathrm{~m}$-equiv/litre above the resting level. In particular we were unable to find either an early or a late rise in gastric acid.

\section{SUMMARY}

The present position of the electrical stimulation test to prove completeness of gastric nerve section during vagotomy is described. The clinical results in some 600 cases are recorded and the insulin test is compared.

This work has been aided by a grant from the WennerGrenska Samfundet, Stockholm.

\section{REFERENCES}

Burge, H. W., Gill, A. M., and Lewis, R. H. (1964). Results of vagotomy with the electrical stimulation test: an interim report. Brit. med. J., 2, 17-21.

- and Vane, J. R. (1958). Method of testing for complete nerve section during vagotomy. Ibid., 1, 1, 615-618. 